\title{
Neurosciences in Buddhist India
}

\author{
Arushi Kumar ${ }^{1}$ Raj Kumar ${ }^{2}$ \\ ${ }^{1}$ Dr. Sampurna Nand Medical College, Jodhpur, Rajasthan, India \\ 2U.P. University of Medical Sciences, Saifai, Etawah, India
}

\begin{abstract}
Address for correspondence Raj Kumar MS, MCh, PhD, DSc, FRCS, FAMS, FNS, FASET, NRCS, MINASc, U.P. University of Medical Sciences, Saifai 206130, Uttar Pradesh, India (e-mail: rajkumar1959@gmail.com).
\end{abstract}

\begin{abstract}
Keywords

- medicine in Buddhist era

- Buddhist ethics

- medicine and surgery in Buddhist India

Neurosciences in Buddhist era was mainly based on power of mind and thoughts. It emphasized mainly about the power of mind, control of thoughts, purification, and modifications of erroneous thought process, which should result in truthful and correct practices and subsequent actions by human beings to remain happy. Buddhism believes that most diseases of human body are secondary to mind and that these can be healed by controlling the erroneous thoughts and practices of Dhamma. Though the treatment for neurologic disorders such as headache, stress, and anxiety was primitive, it was mainly based on purification of mind and righteous pathway of Dhamma followed by medicines, modification in dietary and other living habits, etc. Enough evidence (including operated case-based commentary) shows that cranial surgery was also performed following appropriate diagnosis. The concept of diagnosis, preoperative evaluation, explanation to the patient, operative procedure, perioperative care, and follow-up was also present in that era.
\end{abstract}

\section{Introduction}

Buddha himself knew Ayurveda other than his disciples such as Jivaka, who was an acclaimed physician of that time and of Buddha himself. In Buddhism, morality has been used as form of medicine. Ayurveda flourished in India with rise of Buddhism, which was later brought to Tibet with establishment of Dhamma. It is important to note that Charaka, the cofounder of classic Ayurveda, was Buddhist. Buddhist medicine was mainly based on morality and one's karmic backlogs, although occasionally the karmic roots go back to previous births. Mind becomes the basis of illness and the ultimate cure lies in mind. ${ }^{1}$ Mind dominates most acts of human being because all types of karma take birth in mind first. ${ }^{2}$ In this article, we have tried to analyze the level of neurosciences practices available at that time to treat the neurologic ailments. The evidence pieces are collected from spiritual teachings. ${ }^{1}$

\section{Material and Method}

It should be noted here that Buddhist literature is written for spiritual and religious reasons; hence, a research in medicine is obviously limited and fragmented. The information collected may also be inadequate and scattered as it has been taken from remote history. ${ }^{3}$ Pali literature does not say directly about medical issues in modern scientific manner, but it is collected through reading the spiritual text, spirituality, and commentaries at different places on varying issues. The data in this article are mainly collected from a book Science of Medicine and Surgery in Buddhist India. ${ }^{3}$ The author of this book has searched the available literature of mainly 6th century BC and rule of king Harshavardhana. ${ }^{3}$ The help of other books on Buddhist literature was also taken while collecting the information and noted concepts.

\section{Observation and Result}

The surgeries were carried out on 11 types of disease in different body parts, and description of 71 surgical instruments could be fetched out from Buddhist literature. It is revealing that Sushruta mentioned about 120 surgical instruments that he used in Ayurveda. ${ }^{3-5}$

\section{Practices of Neurology}

A monk named Pilindavaccha had the problem of severe headache. His head tended to be hot during headache. He received

September 24, 2018

accepted

October 24, 2018
DOI https://doi.org/

10.1055/s-0038-1676669 ISSN 2277-954X.
(C)2018 Neurological Surgeons'

Society of India
License terms

$(\circledast) \Theta \circledast$ 
was advised to put oil on his head, which did not yield any response. Then the nose oil treatment was advocated, but hot oil was used in his case. When oil started trickling, he was advised to make use of a dual nasal instrument in order to have equal flow of oil in both the nostrils. When headache was not subsided, the monk was advised smoke inhalation. In such type of treatment, essences were burnt to cause whirls around (encircling) the wick and the patient had to inhale such smoke. Smoke tubes were also introduced to avoid burn in the throat. ${ }^{3}$

Jivaka Komarabhacca treated many patients with different ailments including headache, treated by medicines or by performing surgery depending on his clinical diagnosis. One of his patients was a merchant's wife who had history of headache for 7 years. Jivaka treated her by the nose oil treatment. The oil was mixed with medicines. The oil slowly came out through the mouth, and the patient was allowed to spit out. She was ultimately cured. ${ }^{3}$

The great philanthropist named Anathpindaka also had problem of severe headache. He was advised to concentrate on five organs of senses by monk Sariputra. These were the eyes, ear, nose, tongue, and body whereby his mind will realize its related dependency on them. This will lead him to control on earthly, watery, fire, and wind elements in the body, which play an important role in human disease. This type of medication was practiced mainly by monks, as yogic practices. $^{3,4}$

\section{Psychology-Related Problems}

Two main types of diseases were noted in mental disorder: (1) “Kayika (bodily) and (2) Cetasika (mental). It was thought that one can know about one's health through the mind within short time and mind can diagnose one's disease. Mind plays an important role in good health. Buddhist literature shows (Anguttara Nikaya) that a nun named Savatthi was always sick and gloomy. She was advised by monk Anada to be careful of five things: (1) diet, (2) not to take non-nutritional food, (3) discard craving regarding the body, (4) discard pride for your body, and (5) discard desire for sex. These five causes can pull down the health to make person unhappy. ${ }^{4}$

\section{Neurosurgery}

Jivaka Kumarabhacca practiced three stages of surgery in 6th century $\mathrm{BC}^{5}$ :

1. To observe the patient carefully and make a diagnosis. If Jivaka encountered the surgical problem, he would explain to the relative about the disease and how he would operate on the patient.

2. Then he would operate on the patient. Sometimes even relatives were allowed to watch the procedure.

3. Following surgery he would instruct the relatives to give the patient rest, medicines, and diet.

\section{Case}

At Rajagaha a certain merchant had headache for 7 years. Jivaka was invited. He made the diagnosis and decided to do a cranial surgery. Before operation, he explained to the patient that after the surgery the patient will have to lay down in bed for 7 months on one side, followed by another 7 months on other side and further 7 months on the back side. The patient willingly agreed and said "Sir, I will abide your instructions; if you cure me, I shall become your servant (dasa)." Because the cranial surgery is very risky, it requires longer time to recoup; therefore, Jivaka had to prepare the patient mentally. This can be called "Pubba-Kammam" meaning preoperative state. ${ }^{4,5}$

Jivaka then made the patient lie down on the bed and tied him to it properly. He opened the skull and took out two living worms (panake), which caused the headache. He sewed the skull with suture and stitched the skin of the head. In the end, he applied an ointment on the wound. This stage was called "Padhana Kamma" meaning intra- and perioperative care. ${ }^{5}$

After the surgery was over, Jivaka used to visit and see the patient's condition. Jivaka on the eighth day visited the patient who requested Jivaka to allow him to sleep on the other side. Jivaka granted him permission. After 7 days when Jivaka visited the patient, he again requested to allow him to lie on the back. Jivaka gave consent to him. After 7 days Jivaka said to the patient, "You can get up now; you are free from the ailment. Three weeks are over, but I have purposely instructed you to lie down for twenty-one months, so that you will be prepared mentally and bear this long duration." This was the third state, that is, "Paccha Kamman" meaning postoperative care. ${ }^{5}$

\section{Discussion}

It is apparent from the available literature that headache was a common ailment of that era as also seen in modern neurology practices. The application of oil on the head was prescribed to relieve the pain to begin with. If it did not relieve the headache, oil was instilled in the nostrils. Because an exact amount of oil was recommended, nose spoons were also designed and prescribed for such applications. Inhalation of aroma or smoke through the nose was also practiced. Smoke was produced by smearing medicinal leaves or drugs on fire. Use of pipe for this purpose was also recommended. ${ }^{4,5}$ It seems from the case reports that the treatment was introduced in sequential and scientific manner at that time also. It is revealing that three cases of headache were prescribed different treatments including surgery, which implies the concept of diagnosis, most probably based on either clinical evaluation or intuitions of the treating physician. It is also noted that the same physician was treating case either by medicine or by surgery, as evident by the example of Jivaka. It is interesting to understand that the Buddhist monks were also trained to treat some diseases as noted by the example of monk Sariputtra, who also treated one case of headache initially (narrated in Majjhima Nikaya). ${ }^{4}$

We get a specific and clear description of surgical instruments in Ayurvedic treatises. Sushruta mentioned 121 instruments used for surgery. ${ }^{3,4} \mathrm{He}$ divided these instruments into six groups, most probably according to their use. It indicates that the instruments were devised according to need of surgical diseases in Ayurvedic surgical practices. Jivaka, a 
pioneer Indian surgeon of the time, performed surgery for different diseases. Jivaka's method of treatment remained different to an individual, depending on the diagnosis of disease most probably. We know that he treated two patients with the same disease in two different ways. A woman who had headache for 7 years was treated with medication. He treated her by putting medicated oil in her nostrils through "Natthu-Karani," and she was completely cured. ${ }^{4}$

Jivaka treated a male patient with the ailment, that is, headache, for 7 years. He examined the patient carefully to reach the diagnosis, explained the disease to him and his family, explained the surgical procedure to be carried out, discussed the risk involved, and prepared him and his family mentally for the postoperative precautions and care. Then he opened the skin of the head (sisacavim). ${ }^{5}$ He took out two living creatures (panaka or clots/worms) and said, "He had these two living creatures, penetrated into brain, and if not removed, he would have died within a few days." ${ }^{5}$ It reveals that the pathology was present in brain parenchyma or at least close to meninges; therefore, he talked about the complication of brain penetration and death. He stitched the skin and applied a layer of ointment on it. ${ }^{5}$ It is clear from this description that some ointment was also used either to prevent infection or to promote healing. However, it is difficult to say that whether it was some kind of antibiotic ointment or some herbal or herbal-mineral preparation as used in Ayurvedic practices for different purposes. He instructed the patient to lie down on the bed for 21 days. ${ }^{5}$ It is apparent that Jivaka advocated postoperative healing by rest to the surgical wound of the head in this case. Because the headache was relieved postoperatively, it implies that this headache was caused by either increased intracranial pressure or stretching of inflamed meninges at least.

This type of surgery is seemingly closer to craniotomy of modern times, when the skull was opened to reach the meninges and brain also most probably. The worms (panakas) or living creatures that are mentioned here may be the associated with removal of either clot or even some part of inflamed or necrosed brain parenchyma, which generally causes chronic headache owing to constant pressure on the meninges.

In the same way, evidence of surgery pertaining to 11 types of disease was noted from spiritual literature, which included anal fistula, hernia, hydrocele, surgery in the foot, joint pains, boil and wound, etc. ${ }^{5}$

\section{Conclusion}

It is apparent from spiritual Buddhist literature that:

1. Cranial surgery was also performed in India during Buddhist era, according to the need of case.

2. There was a system of diagnosing neurologic ailments based on clinical evaluation on available and known examination findings. The treatment was executed as per diagnosis, that is, medical or surgical.

3. The concept of pre-, peri-, postoperative, and follow-up care was also very much practiced.

4. Patients and families were explained about the type of treatment to be instituted, before surgery in particular. This was done to have consent from patients and to prepare them mentally.

5. Medical treatment for neurologic disorders such as headache was present, which was started from simple remedies to the interventional level, though primitive.

6. Neuropsychological diseases, their possible causes, and remedies were also practiced.

7. Even Buddhist monks were trained to treat few ailments.

\section{Acknowledgments}

The authors are grateful to Meena Talim for the publication and contribution to Surgery and Medicine in Buddhist Era. The authors thank the writer and publisher of the book.

\section{Conflicts of Interest}

None.

\section{References}

1 Dharmasiri G. In: Dharamasiri, ed. Ethics as Medicine in Book: Fundamentals of Buddhist Ethics, extended 3rd ed. Sri Lanka: Paramita International Buddhist Society Ltd.; 1998:135, 141

2 Negi WD, ed Yamak Vaggo in Book of Dhammpad. Hindi and Kinnauri translation with Hindi commentary. Taiwan: The corporate body of the Buddha Education Foundation; 2003:1, 2

3 Meena T, ed. Introduction in book. In: Science of Medicine and Surgery in Buddhist India. 1st ed. Delhi, India: Buddhist World Press; 2009:X, XI, XIV

4 Meena T, ed. Diseases and remedies. In: Science of Medicine and Surgery in Buddhist India. 1st ed. New Delhi, India: Buddhist World Press; 2009:38-41, 62-63

5 Meena T, ed. Surgery and surgical instruments. In: Science of Medicine and Surgery in Buddhist India. 1st ed. New Delhi, India: Buddhist World Press; 2009:75-78, 80-90 